\title{
Peripheral Neuropathy of the Alcoholic* : I, Aetiological Role of Aneurin and Other B-complex Vitamins
}

\author{
J. FENNELLY, $†$ M.B., B.CH., B.A.O. ; O. FRANK, PH.D. ; H. BAKER, PH.D. ; C. M. LEEVY, M.D.
}

Brit. med. F., 1964, 2, 1290-1292

Peripheral neuropathy in alcoholics is usually attributed to a lack of aneurin (Victor and Adams, 1961); however, it is often not possible to document this relation by diagnostic or therapeutic tests. Demonstration that pantothenic acid (Hodges et al., 1958) or pyridoxine (Biehl and Vilter, 1954) deficiency may cause peripheral nerve dysfunction suggests that lack of these or other B-complex vitamins may also contribute to neuropathy in the malnourished alcoholic. The present investigation was therefore undertaken to evaluate further the role of aneurin and other B-complex vitamins in the development of this condition. The study consisted of (a) determining circulating levels of aneurin, riboflavin, nicotinic acid, pantothenic acid, biotin, pyridoxine, vitamin $\mathrm{B}_{12}$, and folic acid in alcoholic patients with and without neuropathy ; and $(b)$ an evaluation of the responsiveness of patients with neuropathy to various members of the B-complex group.

\section{Materials and Methods}

Studies were conducted on 20 healthy volunteers and 49 in-patients with a history of chronic alcoholism, 32 of whom had evidence of peripheral neuropathy. Each of the patients with alcoholism had a history of prolonged dietary inadequacy ; 16 were admitted to hospital because of peripheral neuropathy, 16 because of symptoms incident to liver disease, 12 because of active or impending delirium tremens, 3 because of pneumonia, and 2 because of pancreatitis. History revealed that none of the 32 patients with peripheral neuropathy had normal dietary habits (grade 1), 12 had eaten well except during drinking bouts (grade 2), 14 had ingested diets grossly deficient in animal and vegetable proteins (grade 3), and 6 had principally eaten carbohydrate-containing foods for prolonged periods (grade 4). Estimation of alcohol consumption revealed that seven patients drank alcoholic beverages in moderate quantity, not exceeding a total of 2 pints $(1,140 \mathrm{ml}$.) of whisky or its equivalent each week (grade 1) ; 10 patients consumed an equivalent 1 to 2 pints (570-1,140 ml.) of whisky daily for several days or weeks followed by a remission (grade 2), and 12 patients were chronic users of alcohol, consuming an equivalent of 1 to 2 pints $(570-1,140 \mathrm{ml}$.) of whisky daily for several months, or until admitted to hospital (grade 3). Physical examination revealed clinical stigmata of liver disease in 18 patients with peripheral neuropathy and 10 patients without peripheral neuropathy. Five patients had Wernicke's encephalopathy, 5 had clinical evidence of pellagra, 12 had tongue signs of nicotinic acid or riboflavin deficiency, and 2 had ocular signs of riboflavin deficiency.

Fourteen patients had grade I neuropathy, characterized by paraesthesias, muscle cramps, burning feet; in this group objective signs were limited to a reduction in pain and vibratory

- From the Division of Hepatic Metabolism and Nutrition, Department of Medicine, Seton Hall College of Medicine and Jersey City Medical Center. Supported in part by grants TI AM-5236-04, AM04437-04, MH-05541-03 from the National Institutes of Health. Clinical Research Center grant OG-17R1; a grant from the National Clinical Research Center grant OG-17R1; a grant from the National
Vitamin Foundation; and a grant from the New Jersey State Department of Health, Division of Chronic Illness Control.

+ Formerly Research Fellow in Medicine, Seton Hall College of Medicine; at present Director of the Chemotherapy Unit, University College Dublin, Dublin, Ireland. sensation without reflex changes. Ten patients had grade II neuropathy, characterized by marked sensory changes accompanied by decrease in reflexes, and eight patients had grade III neuropathy with severe sensory impairment, absence of reflexes, muscle-wasting, and foot-drop.

Each of the patients had a series of liver-function tests and measurement of circulating levels of B-complex vitamins. A liver biopsy, spinal tap, and electrophysical nerve-function studies were performed in the alcoholic group. Liver-function tests included serum bilirubin (Malloy and Evelyn, 1937), sulphobromophthalein excretion (Mendenhall and Leevy, 1961), serum alkaline phosphatase (Bodansky, 1933), cephalin flocculation test (Hanger, 1938), serum transaminases (Wroblewski and LaDue, 1956), and serum proteins (Campbell and Hanna, 1937). Liver biopsy was performed with the Vim-Silverman needle without complications. B-complex vitamin levels were determined by microbiological techniques employing Ochromonas danica for aneurin and biotin; Tetrahymena pyriformis for riboflavin, nicotinic acid, and vitamin $\mathrm{B}_{6}$ complex; Lactobacillus arabinosus for pantothenic acid; Ochromonas malhamensis for vitamin $\mathrm{B}_{12}$; and Lactobacillus casei for folic acid (Baker and Sobotka, 1962). Selected patients had measurement of muscle and urinary aneurin, estimation of red-bloodcell transketolase activity (Brin et al., 1958), and measurement of blood keto-acids (Friedmann and Haugen, 1943).

Responses to vitamin therapy were evaluated in 29 patients with neuropathy (see Table). These patients were treated in the Clinical Research Center or a special rehabilitation ward, and received a diet containing $700 \mathrm{~m} \mu \mathrm{g}$. of aneurin, $20 \mathrm{~m} \mu \mathrm{g}$. of nicotinic acid, $250 \mathrm{~m} \mu \mathrm{g}$. of pantothenic acid, $50 \mathrm{~m} \mu \mathrm{g}$. of pyridoxine, $5 \mathrm{~m} \mu \mathrm{g}$. of folic acid, and $45 \mu \mathrm{g}$. of vitamin $\mathrm{B}_{12}$. Aneurin $10 \mathrm{mg}$. was given intramuscularly each day and serial observations were made on the effect of this treatment on neuropathy. Patients with a decrease in circulating levels of nicotinic acid, pantothenic acid, pyridoxine, folic acid, and/or vitamin $B_{12}$ who failed to show improvement in neurological status after 10 days of aneurin therapy were treated with the deficient vitamin. Fifty $\mathrm{mg}$. of nicotinic acid, $200 \mathrm{mg}$. of pantothenic acid, or $50 \mathrm{mg}$. of pyridoxine was first given daily on an individual basis according to a predetermined randomized schedule. Daily supplements of $5 \mathrm{mg}$. of folic acid and 1,000 $\mu \mathrm{g}$. of vitamin $\mathrm{B}_{12}$ were finally added to the therapeutic regimen.

\section{Results}

The blood aneurin was significantly lower than normal in $44 \%$ of alcoholic patients without neuropathy, and in $86.2 \%$ of patients with neuropathy. The mean blood aneurin was $43 \pm 17.2 \mathrm{~m} \mu \mathrm{g} . / \mathrm{ml}$. in normal subjects, $25 \pm 11 \mathrm{~m} \mu \mathrm{g}$. in alcoholics without neuropathy, and $14.1 \pm 9.6 \mathrm{~m} \mu \mathrm{g}$. in alcoholics with neuropathy (Fig. 1). Low blood aneurin was regularly associated with reduced urinary excretion of aneurin and decreased muscle content of this vitamin. A good correlation was noted between red-blood-cell transketolase activity and blood aneurin in subjects without significant liver disease; enzyme and vitamin levels often showed no relation in aneurindeficient patients with cirrhosis (Fennelly et al., 1963). 
Therapeutic Response of Alcoholic Patients with Peripheral Neuropathy and Hypovitaminaemia

\begin{tabular}{|c|c|c|c|c|c|c|c|c|c|c|c|}
\hline \multirow{2}{*}{$\begin{array}{l}\text { Case } \\
\text { No. }\end{array}$} & \multirow{2}{*}{$\begin{array}{c}\text { Alcoholism } \\
\text { Grade }\end{array}$} & \multirow{2}{*}{$\begin{array}{l}\text { Dietary } \\
\text { Intake } \\
\text { Grade }\end{array}$} & \multirow{2}{*}{$\begin{array}{l}\text { Neuro- } \\
\text { pathy } \\
\text { Grade }\end{array}$} & \multirow{2}{*}{$\begin{array}{c}\text { Hepatic* } \\
\text { Abnor- } \\
\text { malities }\end{array}$} & \multirow[b]{2}{*}{ Liver Histology } & \multicolumn{4}{|c|}{ Laboratory Findings } & \multicolumn{2}{|c|}{$\begin{array}{l}\text { Neurological Response } \\
\text { to Therapy }\end{array}$} \\
\hline & & & & & & $\begin{array}{c}\text { BSP } \\
45 \text { min. } \\
\% \\
\%\end{array}$ & $\begin{array}{c}\text { Serum } \\
\text { Alb./Glob. } \\
\text { g.\% }\end{array}$ & $\begin{array}{c}\text { Hct. } \\
\%\end{array}$ & Hypovitaminaemia & $\begin{array}{l}\text { Time } \\
\text { Period }\end{array}$ & $\begin{array}{c}\text { Vitamin } \\
\text { Responded To }\end{array}$ \\
\hline \begin{tabular}{|l|}
1 \\
2 \\
3 \\
4 \\
5 \\
6 \\
7 \\
8 \\
9 \\
10 \\
11 \\
12 \\
13 \\
14 \\
15 \\
16 \\
17 \\
18 \\
20 \\
21 \\
22 \\
23 \\
24 \\
25 \\
26 \\
27 \\
28 \\
29
\end{tabular} & $\begin{array}{l}2 \\
1 \\
2 \\
2 \\
3 \\
2 \\
3 \\
2 \\
1 \\
2 \\
3 \\
1 \\
1 \\
2 \\
1 \\
3 \\
3 \\
2 \\
3 \\
2 \\
3 \\
2 \\
2 \\
3 \\
2 \\
3 \\
3 \\
3 \\
2\end{array}$ & $\begin{array}{l}4 \\
4 \\
2 \\
4 \\
3 \\
3 \\
2 \\
2 \\
2 \\
2 \\
2 \\
3 \\
3 \\
3 \\
2 \\
3 \\
3 \\
3 \\
3 \\
2 \\
3 \\
4 \\
4 \\
3 \\
2 \\
4 \\
2 \\
2 \\
2\end{array}$ & \begin{tabular}{|c|} 
I \\
I \\
I \\
I \\
I \\
I \\
I \\
I \\
I \\
I \\
I \\
I \\
I \\
II \\
II \\
II \\
II \\
II \\
II \\
II \\
III \\
III \\
III \\
III \\
III \\
III \\
III
\end{tabular} & $\begin{array}{l}\text { H, A } \\
\text { H } \\
\text { H, } \\
\text { H, A } \\
\text { H } \\
\text { H } \\
\text { H } \\
\text { H } \\
\text { H, S, J } \\
\text { H } \\
\text { H } \\
\text { A, H } \\
\text { H, A } \\
\text { H, S, A } \\
\text { H, J } \\
\text { H, J } \\
\text { H, S, A } \\
\text { J S, J } \\
\text { J, A, J } \\
\text { H } \\
\text { H }\end{array}$ & 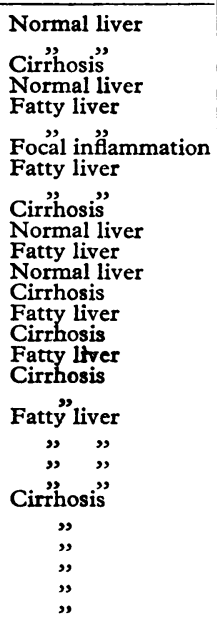 & $\begin{array}{r}1 \\
10 \\
21 \\
21 \\
4 \\
1 \\
7 \\
1 \\
0 \\
10 \\
8 \\
3 \\
0 \\
20 \\
44 \\
10 \\
21 \\
22 \\
21 \\
12 \\
29 \\
22 \\
19 \\
22 \\
30 \\
25 \\
20 \\
14 \\
13\end{array}$ & 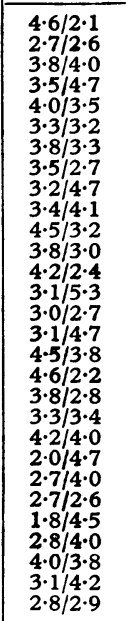 & $\begin{array}{l}39 \\
39 \\
38 \\
33 \\
33 \\
38 \\
39 \\
50 \\
36 \\
35 \\
42 \\
36 \\
36 \\
40 \\
40 \\
40 \\
34 \\
52 \\
40 \\
38 \\
34 \\
28 \\
30 \\
28 \\
33 \\
33 \\
40 \\
41 \\
25\end{array}$ & 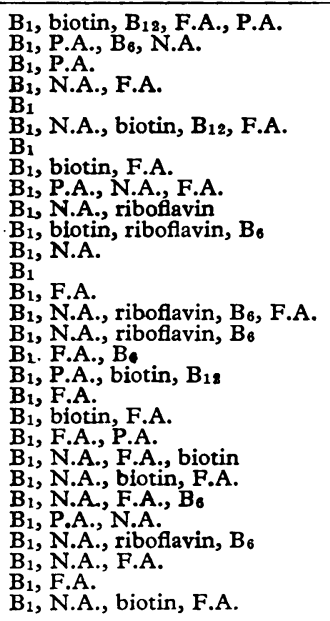 & 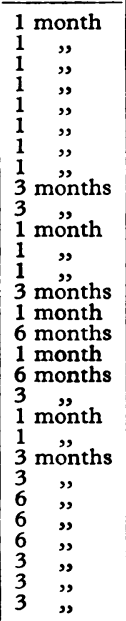 & $\begin{array}{l}\text { Pantothenic acid } \\
\text { Nicotinic acid } \\
\text { Aneurin } \\
\text { ", } \\
\text { ", } \\
\text { ", } \\
\text { \#" } \\
\text { Pyridoxine } \\
\text { Nicotinic acid } \\
\text { Aneurin } \\
\text { No response } \\
\text { Aneurin } \\
\text { No response } \\
\text { Aneurin } \\
\text { No response } \\
\text { Aneurin } \\
\text { Nicotinic acid } \\
\text { Aneurin } \\
\text { No response } \\
\text { ", ", } \\
\text { ", } \\
\text { Aneurin } \\
\text { ", }\end{array}$ \\
\hline
\end{tabular}

*H. $=$ Hepatomegaly. S $=$ Splenomegaly. A $=$ Ascites. J = Jaundice.
t F.A. $=$ Folic acid. P.A. = Pantothenic acid. N.A. $=$ Nicotinic acid.

A low serum folic acid was the second most frequently encountered abnormality, being present in $61 \%$ of those without neuropathy and $69 \%$ of those with neuropathy. Low circulating biotin, vitamin $B_{6}$, pantothenic acid, riboflavin, and vitamin $\mathrm{B}_{12}$ were encountered in $31 \%, 24 \%, 18 \%$, and $10 \%$ respectively of alcoholics with neuropathy (Fig. 2). Combined vitamin B deficiencies were present in $90 \%$ of patients with peripheral neuropathy. A low aneurin was accompanied by a significant reduction in folic acid in $45 \%$, nicotinic acid in $42 \%$, biotin in $24 \%$, vitamin $B_{6}$ in $24 \%$, riboflavin in $17 \%$, pantothenic acid in $14 \%$, and vitamin $B_{12}$ in $10 \%$ of patients.

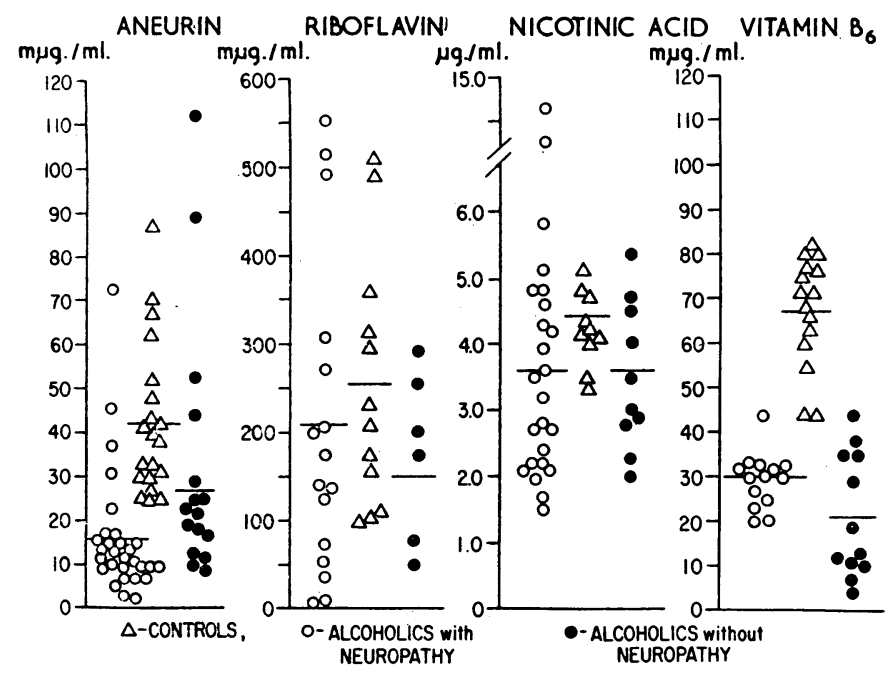

FIG. 1.-Circulating levels of aneurin, riboflavin, nicotinic acid, and vitamin $B_{0}$ in healthy controls, alcoholics with neuropathy, and alcoholics without neuropathy.

Vitamin levels were lowest in patients exhibiting clinical stigmata of deficiency. Patients with Wernicke's encephalopathy had aneurin levels of $2.5,3,6,7$, and $10 \mu \mathrm{g} . / \mathrm{ml}$. Two patients with corneal changes attributed to riboflavin deficiency had blood riboflavin levels of 13 and $39 \mathrm{~m} \mu \mathrm{g} . / \mathrm{ml}$. Patients with diarrhoea, encephalopathy, or skin changes compatible with pellagra had a mean blood nicotinic acid level of $2.6 \mu \mathrm{g} . /$ $\mathrm{ml}$. Seventy per cent. of patients with a low serum folic acid had macrocytosis, anaemia, and/or bone-marrow changes compatible with folic-acid deficiency.
There was no correlation between circulating vitamin levels and severity of alcoholism. The mean blood aneurin level in patients with grade 1 alcoholic consumption was $17 \mu \mathrm{g} . / \mathrm{ml}$. ; in those classified as grade 2 alcoholic consumption it was 18 $\mu \mathrm{g} . / \mathrm{ml}$. ; and in those classified as grade 3 alcoholic consumption it was $17 \mu \mathrm{g} . / \mathrm{ml}$. In contrast, a direct relation was noted between hypovitaminaemia and dietary deficiency. The most marked reduction in circulating vitamin levels occurred in patients subsisting principally on alcoholic beverages and carbohydrate-containing foods. Mean blood aneurin level in patients with a dietary intake classified as grade 1 was $27 \mathrm{~m} \mu \mathrm{g} . / \mathrm{ml}$., in those classified as grade 2 it was $13 \mathrm{~m} \mu \mathrm{g} . / \mathrm{ml}$., in those classified as grade 3 it was $14 \mathrm{~m} \mu \mathrm{g} . / \mathrm{ml}$., and in those classified as grade 4 it was $10 \mathrm{~m} \mu \mathrm{g} . / \mathrm{ml}$.

Mean circulating levels of aneurin, riboflavin, nicotinic acid, biotin, and vitamin $B_{6}$ were lower in malnourished alcoholics with fatty liver and cirrhosis than those with normal liver (Leevy et al., 1964). An increase in serum pantothenic acid was often present in fatty liver, whereas an increase in serum vitamin $\mathrm{B}_{12}$ occurred with active liver-cell necrosis.

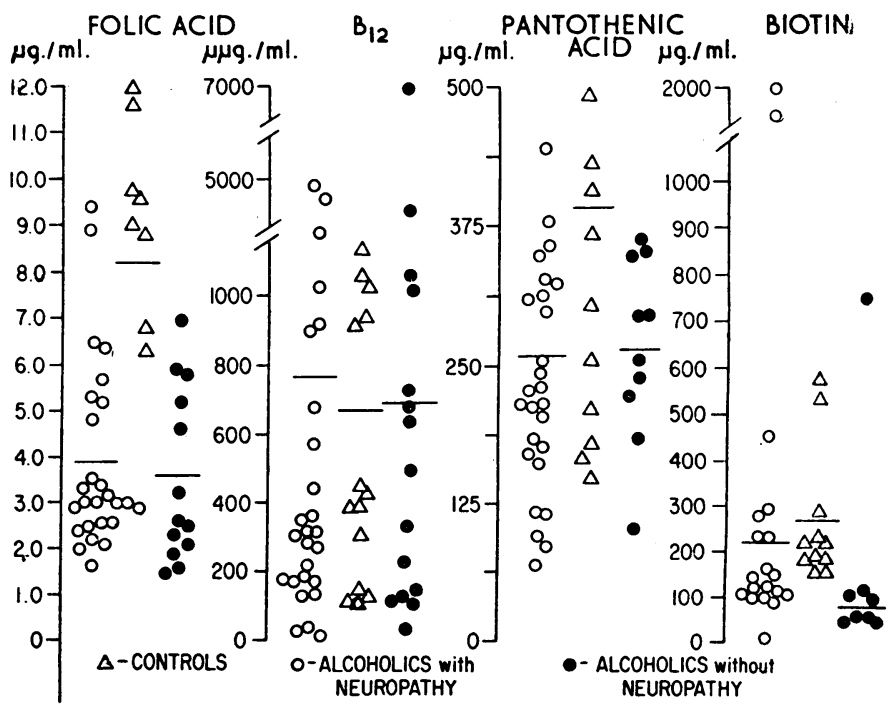

FIg. 2.-Circulating levels of folic acid, vitamin $B_{123}$ pantothenic acid, and biotin in healthy controls, alcoholics with neuropathy, and alcoholics
without neuropathy. 
Response to the therapeutic programme depended upon the severity of neuropathy and presence or absence of severe cirrhosis. Aneurin replacement caused marked improvement in signs of neuropathy in 7 out of 13 patients with grade I neuropathy, and in three out of eight patients with grade II neuropathy within a four-week period (see Table). In these patients, symptoms, pain, and vibratory sensations began to improve within 7 to 10 days. Aneurin caused slower but definite improvement in one patient with grade I neuropathy and in one with grade II neuropathy. None of the patients with grade III neuropathy showed clinical improvement during the initial four-week period of treatment ; four out of eight showed improvement after three to six months of therapy. Three patients with grade I neuropathy, four with grade II neuropathy, and four with grade III neuropathy did not respond to aneurin. This was attributed to the presence of a deficiency of other vitamins in five patients, the presence of severe liver disease, and inability to utilize administered aneurin in four patients (Fennelly et al., 1964), and the irreversibility of neuropathy in two patients. Disappearance of signs and symptoms of neuropathy refractory to aneurin therapy occurred after correction of a low circulating nicotinic acid in two patients with grade I neuropathy and one patient with grade II neuropathy. Identical effects were noted after correction of a low serum pantothenic acid in a patient with grade I neuropathy, and after restoration of a normal vitamin $B_{6}$ level in a patient with grade II neuropathy.

\section{Discussion}

The present study confirms the primary aetiological role of aneurin deficiency in peripheral neuropathy of the alcoholic and indicates that a decreased pantothenic acid, nicotinic acid, or pyridoxine may also be responsible or contributory. These findings emphasize the importance of measuring all vitamins whenever possible and replacing those that are deficient in alcoholics with peripheral neuropathy. Decreased serum vitamin $B_{12}$ was often present ; however, there was no evidence from therapeutic trials that a deficiency of this vitamin caused neuropathy in this group of patients. Similarly, therapeutic responses suggested that encountered deficiencies of folic acid, riboflavin, or biotin were also not responsible for nerve damage.

Pantothenic acid, pyridoxine, and nicotinic acid deficiency have previously been demonstrated to be important in the development of peripheral neuropathy in non-alcoholic patients. Experimental pantothenic acid deficiency induced by omegamethyl-pantothenic acid is characterized by burning feet (Hodges et al., 1958) ; moreover, the symptom of neuropathy in malnourished Indians is controlled by treatment with pantothenic acid (Gopalan, 1946). Inhibition of pyridoxine activity is responsible for isoniazid-induced neuropathy (Biehl and Vilter, 1954), and a deficiency of nicotinic acid appears to be aetiological in thalidomide-induced peripheral neuritis (Robertson, 1962 ; Frank et al., 1963). Their aetiological role should be expected, since they are often absent from the diet of alcoholics with peripheral neuropathy (Leevy et al., 1964).

The occasional presence of lower circulating levels of Bcomplex vitamins in alcoholics without neuropathy than in those with nerve damage suggests that other factors may contribute to nerve dysfunction. It is possible that observed laboratory evidence of vitamin deficiency was not present long enough to cause nerve impairment in alcoholics without neuropathy. Alternatively, nerve damage may be due to a combination of a vitamin deficiency and other factors such as protein or mineral deficiency and alcohol toxicity. It is clear that nutrients required for conversion of $\mathrm{B}$-complex vitamins to usable forms are essential for preservation of nerve function. Further study is desirable to assess the neurotoxicity of alcohol in the presence of a deficiency state. Also, in clarifying the factors responsible for peripheral neuropathy of the alcoholic it is necessary to delineate the role of hepatic dysfunction in the development of altered nerve dysfunction and interference with its repair. The diseased liver may play a key part in the development of vitamin deficiency, or have a decreased ability to convert free vitamins into metabolically active coenzymes, and deficient capacity to synthesize apoenzymes (Leevy et al., 1964).

\section{Summary and Conclusions}

Circulating B-complex vitamins were measured in alcoholic patients with and without peripheral neuropathy and results compared with values obtained in healthy control subjects. Eighty-six per cent. of alcoholics with peripheral neuropathy had a significant decrease in circulating aneurin. A concomitant decrease in circulating riboflavin, nicotinic acid, pantothenic acid, biotin, vitamin $\mathrm{B}_{6}$ complex, folic acid, and/or vitamin $B_{12}$ was present in $90 \%$ of this group.

A reduction in circulating aneurin and other B-complex vitamins was present in $44 \%$ of alcoholics without neuropathy. The mean level of circulating B-complex vitamins was significantly lower in alcoholics with neuropathy than in those without this sign. Hypovitaminaemia showed no correlation with ethanol consumption, but was directly related to previous dietary habits.

Replacement of deficient aneurin was associated with improvement in 8 out of 13 patients with grade I neuropathy, in four out of eight with grade II neuropathy, and in four out of eight with grade III neuropathy. Of the patients with grade I and II neuropathy who were refractory to aneurin, two responded to addition of nicotinic acid, one to pantothenic acid, and one to pyridoxine. Refractoriness to all measures occurred in seven patients with grade II and III neuropathy, six of whom had severe liver disease.

We are grateful to Dr. Richard Chambers and Dr. George Dauzier, of the Division of Neurology, for their advice and help during these studies.

\section{REFERENCES}

Baker, H., and Sobotka, H. (1962). Advanc. clin. Chem., 5, 173. Biehl, J. P., and Vilter, R. W. (1954). Proc. Soc. exp. Biol. (N.Y.), 85,

Bodansky, A. (1933). f. biol. Chem., 101, 93.

Brin, M., Shohet, S. S., and Davidson, C. S. (1958). Ibid., 230, 319.

Campbell, W. R., and Hanna, M. I. (1937). Ibid., 119, 15.

nnelly, J., Baker, H., Frank, O., and Leevy, C. M. (1963). Clin. Res., 11, 182.

Frank, O., Baker, H., and Leevy, C. M. (1964). Proc. Soc. exp. Biol. (N.Y.), 116, 875 . Frank, O., Baker, H., Ziffer, H., Aaronson, S., Hutner, S., and Leevy,
C. M. (1963). Science, 139, 110 .

Friedmann, T. E., and Haugen, G. R. (1943). f. biol. Chem., 147, 415. Gopalan, C. (1946). Indian med. Gaz., 81, 22.

Hanger, F. M. (1938). Trans. Ass. Amer. Phycns, 53, 148.

Hodges, R. E., Ohlson, M. A., and Bean, W. B. (1958). F. clin. Invest., 37, 1642 .

Leevy, C. M., Baker, H., tenHove, W., Frank, O., and Cherrick, G. R. (1964), Ann. intern. Med., 60, 721.

Malloy, H. T., and Evelyn, K. A. (1937). 7. biol. Chem., 119, 481. Mendenhall, C. L., and Leevy, C. M. (1961). New Engl. f. Med., 264,
431.

Robertson, W. F. (1962). Brit. med. f., 1, 792.

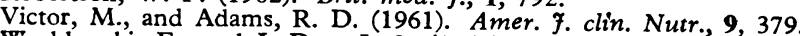

Wroblewski, F., and LaDue, J. S. (1956). Proc. Soc. exp. Biol. (N.Y.), 